\title{
Review of the Greenland Summit Ice Cores CD-ROM
}

tion. One of our greatest challenges is to achieve widespread sharing and integration of data without compromising data quality, and in a way that fully acknowledges and, wherever possible, highlights the role of all who provide data for use by the wider scientific community. This requires a high level of cooperation and mutual trust between the many data providers and the smaller number of scientists who manage the data, or work with data in a synoptic way as part of their own research efforts. It is all too easy to reinforce the asymmetry of this relationship in thoughtless ways. In introducing this issue of the Newsletter, we therefore take the opportunity to emphasize the following:

- all publications using data produced by other scientists have an obligation to clearly acknowledge these other scientists, and to cite the publications where the data were first presented

- a similar obligation rests with all those who use data produced by others in oral presentations, particularly when presentations are made at high-profile national or international conferences

- all who peer-review scientific publications have the responsibility to make sure data sources are always acknowledged and/or cited

The data community within PAGES understands that submitting high quality, adequately referenced data to publicly accessible databases is both a selfless acknowledgement of wider research needs and often an act of intellectual altruism, even though it is reinforced by the stated policy of the IGBP and many funding agencies. It places the "receivers", "managers" and "users" under an obligation to find realistic ways of both recognising and rewarding the generosity of all who submit their data. It also reinforces the need for all of us to work towards database access that is truly easy and open to all, irrespective of their location and interests.

The PAGes Scientific Steering Committee The members of the PAGES SSC are listed at http://www.pages.unibe.ch/people/ssc.html
Superlatives abound when discussing the Greenland Summit ice core projects. The two deepest ice cores drilled in the Northern Hemisphere, both investigated in seemingly exhaustive detail by a cast of hundreds to provide two of the longest and most comprehensive paleoclimate data sets available. To aid in a condensation and synthesis of this priceless data set a CD-ROM has now been compiled, containing a large amount of the analysis data from the two projects. It is available free in a self-contained package designed to work on both PC and Macintosh platforms.

The two projects are the Greenland Ice Sheet Project Two (GISP2) and the European Greenland Ice Core Project
(GRIP) under(GRIP) under-
taken
betaken $\begin{gathered}\text { be- } \\ \text { tween } 1989\end{gathered}$ tween 1989
and 1993.
The cores The cores
is e r e
drilled down to the bedrock, over $3000 \mathrm{~m}$, on the summit plateau of the Greenland ice cap about $30 \mathrm{~km}$ apart. The aim was to produce a detailed paleoclimatic record stretching back over 100,000 years. The close proximity of the cores would allow a unique intercomparison of the core data.

I am pleased to say that the CD-ROM is, in general, pretty easy to use and well thought out. From the table of contents there are links to all the main sections: a couple of short introductory articles, the data, a bibliography, an excellent search engine for both authors and analysed data, and a plotting program. The introductory articles describe the basics of the cores, what was measured, and to an extent, the more important results. I was a little disappointed that there was not also a background article included here, explaining "what tells you what". It seems the user must already be familiar with the differences one might expect between say methane and carbon dioxide timeseries, or at least have a text book handy. Some excellent photos in the article would have been more informative with captions.

The primary purpose of the CD-ROM would appear to be to make easily available the large number of data sets produced from the cores. This is done through tables of the data, in a reassuringly simple ascii format. A header describes the data and notes the references that should be cited upon use of the results. Also included on the CD is the PaleoVu plotting package, which is easily run either from the $\mathrm{CD}$ or after downloading onto your computer. The package itself is alarmingly simple, to the extent that it did become a little limited after a while, and for publication quality plots, the user might find it easier to import the relevant data into their favorite plotting program. However the simplicity was , , 